\title{
Letter to the editor of implementation science in response to "Implementation Science in maternity care, A scoping Review" by Dadich, Piper, and Coates (2021)
}

\author{
Rachel Blankstein Breman ${ }^{1 *}$ (D), Rebecca Feldman Hamm² and Jennifer A. Callaghan-Koru ${ }^{3}$
}

\section{Dear Editors:}

Thank you for the recent publication "Implementation Science in maternity care, A scoping Review" by Dadich, Piper, and Coates. As the authors note, preventable maternal morbidity and mortality is an urgent health crisis. Maternity care is plagued by evidence-based practice gaps at two extremes-"too much too soon" and "too little too late." In both high- and low-resource settings, there is underuse of many effective interventions, as well as unwarranted over intervention in normal physiologic labor [1]. As this review demonstrates, maternity care is in great need of implementation research to close these gaps. While we applaud Dadich and colleagues' attention to this important issue, we also have concerns about the study's methodology. Specifically, we believe the authors should have used broader search terms in order to provide a comprehensive assessment of implementation science in maternity care.

The methods state that the search terms were limited to two- "implementation" and "maternity." Restricting the search to articles with the exact term "maternity" provides a vastly incomplete picture of the literature surrounding maternity care. Maternity care is a continuum, encompassing prenatal, intrapartum, and postpartum care, and involves a mix of providers, including

This comment refers to the article available at https://doi.org/10.1186/ s13012-021-01083-6.

* Correspondence: rbreman@umaryland.edu

${ }^{1}$ Department of Partnerships, Professional Education and Practice, School of Nursing, University of Maryland, Baltimore, MD, USA

Full list of author information is available at the end of the article midwives, obstetricians, maternal-fetal medicine specialists, and nurses. Search terms essential to any review regarding maternity care would include perinatal, prenatal/antenatal, labor, intrapartum, obstetric, midwifery, birth, childbirth, postpartum, and maternal. In order to fully understand implementation research within maternity care, we need to consider the different, but related terms that can be employed across studies and settings. We do not consider these terms to be "euphemisms," as suggested in the paper's discussion, but rather critical terms to identify relevant literature within the scope of this review.

A prior systematic search we conducted with broader maternal health search terms identified 58 additional implementation research studies addressing maternity care for the United States alone. We are specifically concerned with the absence of important implementation research studies on critical interventions for the reduction of maternal morbidity and mortality globally:

- The World Health Organization's Safe Childbirth Checklist includes interventions to prevention of morbidity due to hypertension, hemorrhage, infection, and other causes. The BetterBirth trial, a large trial implementing the checklist in India, published multiple reports not captured in the review [2-5]. Implementation of this checklist, with coaching support, yielded equivocal results, an important consideration for future implementation 
initiatives and research in low-resource setting studies.

- Postpartum health and monitoring are also an essential aspect of maternity care. One example is a shelf-stable, relatively inexpensive injection of oxytocin in the third stage of labor to prevent postpartum hemorrhage and death. This practice is frequently referred to as active management of the third stage of labor (AMTSL) [6]. Multiple studies have assessed implementation of AMTSL [7-9], yet none of these or any on this topic were included in the review.

- Overuse of cesarean and underutilization of vaginal birth after cesarean (VBAC) have contributed to maternal morbidity and mortality in more developed countries [10, 11]. Several studies addressing implementation of strategies and practices to prevent primary cesarean birth in countries where overuse is a major challenge to improve birth outcomes were not included in this review [12-14].

We also note the exclusion of published studies utilizing implementation research frameworks and theories in maternity care. We are aware of nine additional studies employing the CFIR in maternity care published during the search period within the USA [15-23]. These studies took place in hospital labor and delivery units, outpatient prenatal/postpartum clinics, and community organizations, and addressed implementation of practices related oral health, obstetric hemorrhage, and long acting reversible contraception, among other interventions. Similar studies may have been overlooked from other countries.

The breadth of maternity care settings, and diversity of implementation constraints between settings, makes it challenging to map this literature in one review paper. Dadich and colleagues, like implementation scientists assessing literature in other clinical areas [24], rightly note the need to promote the consistent application of implementation science theories and frameworks to develop applicable knowledge about how to best support implementation across maternity care settings. We would also advocate for the need to adapt and apply implementation science measures to maternity care. Efforts to synthesize findings across studies that use the same frameworks, theories, and/or measures will be a great asset in advancing implementation science for maternity care. While there remains much work to be done to support implementation in maternity care, ensuring that we learn from all prior research will allow us to more effectively and efficiently target future efforts for the greatest benefit of maternity patients.

\section{Authors' contributions}

RBB initiated the first draft. RFH wrote the second draft. JCK reviewed the literature. The author(s) read and approved the final manuscript.

\section{Funding}

Dr. Breman received funding from the University of Maryland, Baltimore Institute for Clinical and Translational Research Grant \# 1UL1TR003098-01 and the Eunice Kennedy Shriver National Institute Of Child Health \& Human Development of the National Institutes of Health (Award Number R03HD09639). Dr. Hamm received funding from the National Institutes of Health, NICHD grant \#K23HD102523.

Dr. Callaghan-Koru received funding from the Eunice Kennedy Shriver National Institute Of Child Health \& Human Development of the National Institutes of Health (Award Number R03HD09639), the National Heart, Lung, and Blood Institute of the National Institutes of Health (Award Number R01HL146785), and the Health Resources and Services Administration HRSA (Award Number U7AMC33717).

\section{Availability of data and materials}

N/A

\section{Declarations}

Ethics approval and consent to participate $\mathrm{N} / \mathrm{A}$

Consent for publication

We consent to this being published.

\section{Competing interests}

$\mathrm{N} / \mathrm{A}$

\section{Author details}

'Department of Partnerships, Professional Education and Practice, School of Nursing, University of Maryland, Baltimore, MD, USA. ${ }^{2}$ Department of Obstetrics and Gynecology, University of Pennsylvania Perelman School of Medicine, Philadelphia, USA. ${ }^{3}$ Department of Sociology, Anthropology and Public Health, University of Maryland, Baltimore County, Baltimore, USA.

Received: 10 May 2021 Accepted: 18 May 2021

Published online: 16 August 2021

\section{References}

1. Miller S, Abalos E, Chamillard M, Ciapponi A, Colaci D, Comandé D, et al. Beyond too little, too late and too much, too soon: a pathway towards evidence-based, respectful maternity care worldwide. Lancet. 2016; 388(10056):2176-92. https://doi.org/10.1016/S0140-6736(16)31472-6.

2. Semrau KEA, Hirschhorn LR, Marx Delaney M, Singh VP, Saurastri R, Sharma $\mathrm{N}$, et al. Outcomes of a coaching-based WHO safe childbirth checklist program in India. N Engl J Med. 2017;377(24):2313-24. https://doi.org/10.1 056/nejmoa1701075.

3. Kara N, Firestone R, Kalita T, Gawande AA, Kumar V, Kodkany B, et al. The Betterbirth program: pursuing effective adoption and sustained use of the WHO safe childbirth checklist through coaching-based implementation in Uttar Pradesh. India. Glob Heal Sci Pract. 2017;5(2):232-43. https://doi.org/10. 9745/GHSP-D-16-00411.

4. Hirschhorn LR, Semrau K, Kodkany B, et al. Learning before leaping: integration of an adaptive study design process prior to initiation of BetterBirth, a large-scale randomized controlled trial in Uttar Pradesh, India. Implement Sci. 2015;10(1). doi:https://doi.org/10.1186/s13012-015-0309-y

5. Marx Delaney M, Miller KA, Bobanski L, Singh S, Kumar V, Karlage A, et al. Unpacking the null: a post-hoc analysis of a cluster-randomised controlled trial of the WHO safe childbirth checklist in Uttar Pradesh, India (BetterBirth). Lancet Glob Heal. 2019;7(8):e1088-96. https://doi.org/10.1016/S2214-109X(19)30261-X.

6. Berghella V. Management of the third stage of labor after vaginal delivery: drug therapy to minimize hemorrhage. UpToDate. https://www.uptodate. com/contents/management-of-the-third-stage-of-labor-after-vaginaldelivery-drug-therapy-to-minimize-hemorrhage?search=active-managementof-the-third-stage-of-labor\&source=search result\&selectedTitle $=1 \sim 150 \&$ usa ge_type=default\&display_ra. Published 2020 . 
7. Miranda JE, Rojas-Suarez J, Paternina A, Mendoza R, Bello C, Tolosa JE. The effect of guideline variations on the implementation of active management of the third stage of labor. Int J Gynecol Obstet. 2013;121(3):266-9. https:// doi.org/10.1016/j.jigo.2012.12.016.

8. Braddick L, Tuckey V, Abbas Z, et al. A mixed-methods study of barriers and facilitators to the implementation of postpartum hemorrhage guidelines in Uganda. 2015. doi:https://doi.org/10.1016/j.ijgo.2015.06.047, 132, 1, 89, 93

9. Hermida J, Salas B, Sloan NL. Sustainable scale-up of active management of the third stage of labor for prevention of postpartum hemorrhage in Ecuador. 2007. doi:https://doi.org/10.1016/j.ijgo.2012.01.017, 117, 3, 278, 282

10. Martin JA, Hamilton BE, Osterman MJK. Births in the United States, 2018. NCHS Data Brief. 2019;346:7 https://www.cdc.gov/nchs/products/index.htm.

11. Shaw D, Guise J, Shah $\mathrm{N}$, et al. Drivers of maternity care in high income countries: can health systems support woman-centred care? Lancet. 2016; 6736(16):1-14. https://doi.org/10.1016/S0140-6736(16)31527-6.

12. Chaillet N, Dumont A. Evidence-based strategies for reducing cesarean section rates: a meta-analysis. [Review] [72 refs]. Birth. 2007;34(1):53-64. https://doi.org/10.1111/j.1523-536X.2006.00146.X.

13. Callaghan-Koru JA, Creanga AA, DiPietro B, Mark K, Sowe A, Aboumatar N, et al. Implementation of the safe reduction of primary cesarean births safety bundle during the first year of a statewide collaborative in Maryland. Obstet Gynecol. 2019;134(1):109-19. https://doi.org/10.1097/AOG.0000000000003328.

14. Chaillet N, Dumont A, Abrahamowicz M, Pasquier JC, Audibert F, Monnier P, et al. A cluster-randomized trial to reduce cesarean delivery rates in Quebec. N Engl J Med. 2015;372(18):1710-21. https://doi.org/10.1056/nejmoa1407120.

15. Vamos CA, Thompson EL, Cantor A, Detman L, Bronson E, Phelps A, et al. Contextual factors influencing the implementation of the obstetrics hemorrhage initiative in Florida. J Perinatol. 2017;37(2):150-6. https://doi. org/10.1038/jp.2016.199.

16. Vamos CA, Griner SB, Kirchharr C, Green SM, DeBate R, Daley EM, et al. The development of a theory-based eHealth app prototype to promote oral health during prenatal care visits. Transl Behav Med. 2019;9(6):1100-11. https://doi.org/10.1093/tbm/ibz047.

17. DeSisto CL, Kroelinger CD, Estrich C, et al. Application of an implementation science framework to policies on immediate postpartum long-acting reversible contraception. Public Health Rep. 2019;134(2):189-96. https://doi. org/10.1177/0033354918824329.

18. Huebner CE, Milgrom P, Mancl LA, Smolen D, Sutherland M, Weinstein P, et al. Implementation partnerships in a community-based intergenerational oral health study. Community Dent Health. 2014;31(4):207-11. https://doi. org/10.1922/CDH_3378Huebner05.

19. Bernstein JA, Mccloskey L, Gebel CM, Iverson RE, Lee-Parritz A. Lost opportunities to prevent early onset type 2 diabetes mellitus after a pregnancy complicated by gestational diabetes. Care. 2016;4:250. https:// doi.org/10.1136/bmjdrc-2016.

20. Vamos CA, Cantor A, Thompson EL, Detman LA, Bronson EA, Phelps A, et al. The Obstetric Hemorrhage Initiative $(\mathrm{OH})$ in Florida: the role of intervention characteristics in influencing implementation experiences among multidisciplinary hospital staff. Matern Child Health J. 2016;20(10):2003-11. https://doi.org/10.1007/s10995-016-2020-2.

21. Webb J, Sorensen A, Sommerness S, Lasater B, Mistry K, Kahwati L. Advancing perinatal patient safety through application of safety science principles using health IT. BMC Med Inform Decis Mak. 2017;17(1). doi: https://doi.org/10.1186/s12911-017-0572-8

22. Mcardle J, Sorensen A, Fowler Cl, Sommerness S, Burson K, Kahwati L. Strategies to improve management of shoulder dystocia under the AHRQ safety program for perinatal care. JOGNN. 2018;47(2):191-201. https://doi. org/10.1016/j.jogn.2017.11.014.

23. Breman RB, Low LK, Paul J, Johantgen M. Promoting active labor admission: early labor lounge implementation barriers and facilitators from the clinician perspective. Nurs Forum. 2019;55(2):182-9. https://doi.org/10.1111/ nuf.12414.

24. Damschroder LJ. Clarity out of chaos: use of theory in implementation research. Psychiatry Res. 2020;283:112461. https://doi.org/10.1016/j. psychres.2019.06.036

\section{Publisher's Note}

Springer Nature remains neutral with regard to jurisdictional claims in published maps and institutional affiliations.

Ready to submit your research? Choose BMC and benefit from:

- fast, convenient online submission

- thorough peer review by experienced researchers in your field

- rapid publication on acceptance

- support for research data, including large and complex data types

- gold Open Access which fosters wider collaboration and increased citations

- maximum visibility for your research: over $100 \mathrm{M}$ website views per year

At BMC, research is always in progress.

Learn more biomedcentral.com/submissions 